\title{
Landmark-Based Morphometry Reveals Phyllometric Diversity along the Shoot Axis of the Grapevine (Vitis vinifera L.)
}

\author{
BODOR PÉTER ${ }^{1 *}$, BARANYAI LÁSZLÓ ${ }^{2}$, SZEKSZÁRDI ANDREA ${ }^{1}$, \\ BISZTRAY GYÖRGY DÉNES ${ }^{1}$, BÁLO BORBÁlA ${ }^{1}$
}

\begin{abstract}
Leaf morphology of the grapevine (Vitis vinifera L.) cv. 'Kövidinka' was evaluated based on 32 landmarks. The aim of this study was to reveal leaf morphological diversity along the shoot axis. For this purpose 10 shoots were collected with 26 to 35 leaves. Altogether 304 leaf samples were digitised and analysed with the GRA.LE.D 2.04. raster graphic software. Leaf damage was estimated based on the missing landmarks on the lamina. Our results showed that the leaves on the $11^{\text {th }}$ and $13^{\text {th }}$ nodes are the most intact, without missing landmarks. Lowest variability $\left(c_{v}=0,126\right)$ of the investigated 54 morphological characteristics were observed among the leaves on the $11^{\text {th }}$ nodes of the shoots, in accordance with the literature. Based on the results length of the veins, angles between the veins and further features such as size of the serrations show high diversity along the shoot axis. These results underline the need of careful sampling during the ampelometric investigations.
\end{abstract}

Keywords: leaf, Vitis vinifera L., ampelometry, morphology

\section{Introduction}

Grapevine (Vitis vinifera L.) leaf morphology shows high variability among the cultivars but certain traits are homologous. Venation is palmate, built up by five main veins, which arise from a single point at the petiolar junction. These main veins end in lobes. Between the lobes there are sinuses, their depth is typical to each cultivar, just as the angle between the veins, which determines the general leaf shape (Mullins et al., 2004). Leaf morphological characteristics have high importance in grapevine description and identification (OIV, 2009). Since cultivars show variability in size, shape,

\footnotetext{
*Corresponding author. E-mail: Bodor.Peter@kertk.szie.hu

${ }^{1}$ Department of Viticulture, Faculty of Horticultural Science, Szent István University, H-1118 Budapest, Villányi út 29-43.

2Department of Physics and Control, Faculty of Food Science, Szent István University, H-1118 Budapest, Somlói út 14-16.
} 
lobature of the leaf, this organ is in the focus of the ampelographic literature from the very beginning. Ravaz (1902) has been introducing the leaf venation patterning, general leaf shapes, asymmetry, and giving the base of modern ampelometry. This study is based on the metric characterisation of homologous features: length of veins, angles between the veins, opening of the petiole sinus and size of teethes. In the middle of the 20th Century Galet (1956) and Németh (1967) carried out comprehensive characterisation of cultivars according to ampelometry. Beside the manual metric characterisation of the leaf, computer software environments are also frequently used in ampelometry (Alessandri et al., 1996; Soldavini et al., 2009). The above mentioned studies were mainly based on traditional and landmark-based (homologous anatomical points, present on all individuals in a sample set) morphometric measurements with description of the lengths, angles, ratios and outlines. Chitwood et al. (2016a, 2016b) have been introducing geometric morphometry (GMM) in ampelography.

Grapevine leaves show diversity along the shoot axis. This phenomenon is explained with heteroblasty and ontogeny (Chitwood et al., 2016b) and is present not only on Vitis vinifera L. but also on other Vitis species (Cousin and Prins, 2008). Leaf morphological variability along the shoot has already been mentioned by Ravaz (1902), who suggested using the leaves at the $9^{\text {th }}$ to $12^{\text {th }}$ nodes for comparison. Many ampelographers did the same recommendation (Németh, 1967), while others nominate the middle third of the shoots for sampling (OIV, 2009). The aim of this paper is to explore morphological diversity of the 'Kövidinka' grapevine (Vitis vinifera L.) cultivar leaves along the shoot axis and get reliable data which would be used for landmark-based geometric morphometric purpose in the future.

\section{Materials and Methods}

\section{Plant material}

The study was carried out in the experimental field of the Soós István Secondary School at Szigetcsép (Hungary). Leaf samples collected from 'Kövidinka' grapevine (Vitis vinifera L.) cultivar grafted onto Berlandieri $\times$ Riparia T. 5C have been investigated. Vineyard was planted in 1992 with $2 \times 0.8 \mathrm{~m}$ row and vine spacing on head training system with vertical shoot positioning. Vines were pruned with equal bud load, with short spurs. Ten shoots were collected randomly from 10 plants in July 2016. Leaves were 
removed, numbered from the base to the top position and stored in plastic bag until scanning.

\section{Digitalization}

Digitalization of 304 leaves was carried out individually with a HP Scanjet 4570c Scanner on 300 dpi at the Department of Viticulture, Faculty of Horticultural Science, Szent István University.

\section{Landmark coordinate record and graphic reconstruction}

Thirty-two biometric landmarks were recorded with the GRA.LE.D. 2.04. raster graphic software according to Bodor et al. (2012, 2014). Semiautomatic software records the Cartesian coordinates of each landmarks on a sample. Origin of this Cartesian coordinate system is considered the connection point of the petiole where leaf veins arise from.

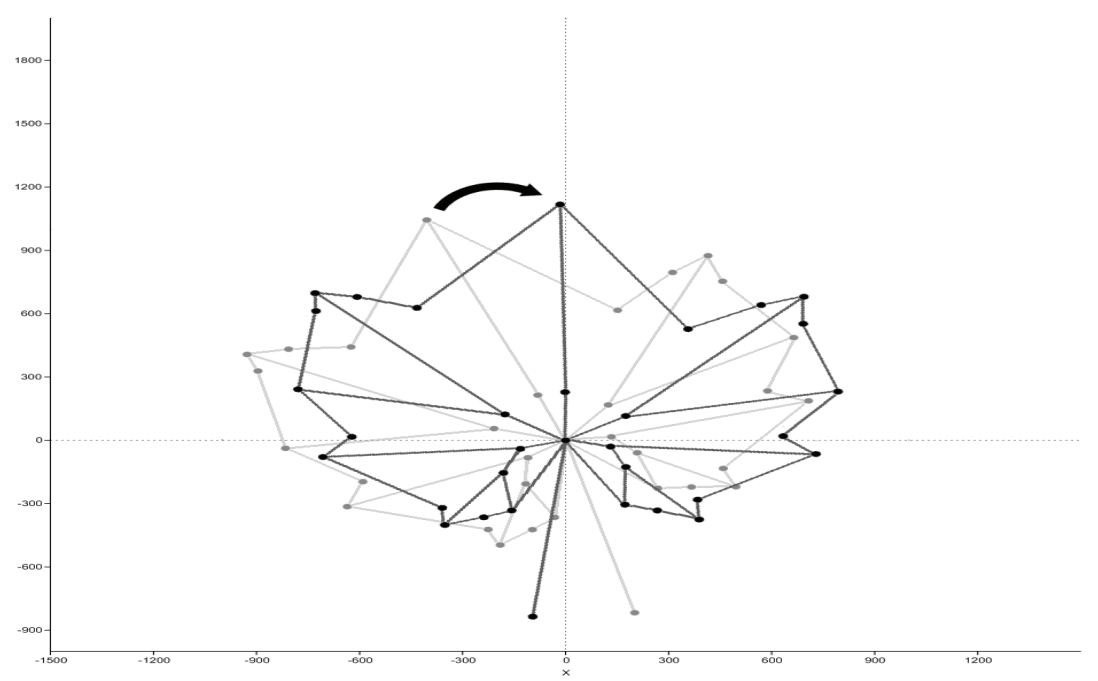

Fig. 1. Rotation of the landmark coordinates around the petiole junction point

Altogether 304 leaf samples were collected and digitalised, however, during the landmark record it was discovered that leaf samples collected above the $25^{\text {th }}$ node are difficult to characterise due to the small size and undifferentiated lobes and sinuses. In this way reliability of the landmarks 
was defined based on a subset of 250 samples collected from the $1^{\text {st }}$ to the $25^{\text {th }}$ node. Presence and absence of the landmarks were explored at all leaf layers at all landmark positions.

Evaluation of the landmark reliability (i.e. the presence on a sample) and diversity of those positions (i.e. the position of the same landmark on different samples) have been carried out. For these purposes, recorded landmark coordinates of all samples were rotated with the $R$ software ( $R$ Core Team, 2014) around the petiole junction until the first branching point of the midvein (Lm4) fit to the y axis (Fig. 1).

Graphic reconstruction of the average leaves at the $1^{\text {st }}, 5^{\text {th }}, 10^{\text {th }}, 15^{\text {th }}, 20^{\text {th }}$ and $25^{\text {th }}$ nodes were carried out based on the average and standard deviations of the coordinate positions with the PAST 2.13 (Hammer et al., 2001). Figures were depicted and completed manually.

\section{Evaluation of landmark and leaf morphological diversity}

Since scanning was carried out with the same resolution at $300 \mathrm{dpi}$, diversity of the coordinates at the same landmark were possible to represent in $\mathrm{mm}$ value ( 1 unit [d] is $0,084666667 \mathrm{~mm}$ on a 300 dpi picture).

Fifty-four leaf morphological characteristics (Bodor et al., 2014) were evaluated: length of the veins, angles between the veins, depth of sinuses, distance between lobe tips, size of the serrations in the top of the lobes. ANOVA analysis was carried out to explore difference among the leaf layers from the $1^{\text {st }}$ to the $25^{\text {th }}$ nodes.

Mean, standard deviation and coefficient of variation $\left(c_{v}=\frac{\sigma}{\mu}\right)$ were calculated for each morphological characteristic at each node according to the 10 collected leaves. In the next step we calculated the average and the standard deviation of the CV values of the 54 morphological characters. These data represent the overall morphological variability at each node. Deviation of the landmark coordinates were analysed at each leaf layer oneby-one along the $\mathrm{x}$ and $\mathrm{y}$ axis and results were statistically evaluated by ANOVA analysis with the PAST 2.13 (Hammer et al., 2001). 


\section{Results}

\section{Landmark coordinate record and graphic reconstruction}

The most reliable landmark was the connection point of the petiole Lm1 (100\% presence in the samples set), while the least consistent was Lm11 where in 18 out of the 250 cases $(7.2 \%)$ this landmark (i.e. tip of the vein) was missing. Landmark absence was possibly caused by senescence of the leaves, hail, pests, or other damage. Most intact leaves were collected from the $11^{\text {th }}$ and $13^{\text {th }}$ nodes of the shoots where all landmarks were present, while highest rate of damage was observed at the $7^{\text {th }}$ node with $90.93 \%$ presence (29 out of the 320 landmarks were missing) (Fig. 2a, 2b).
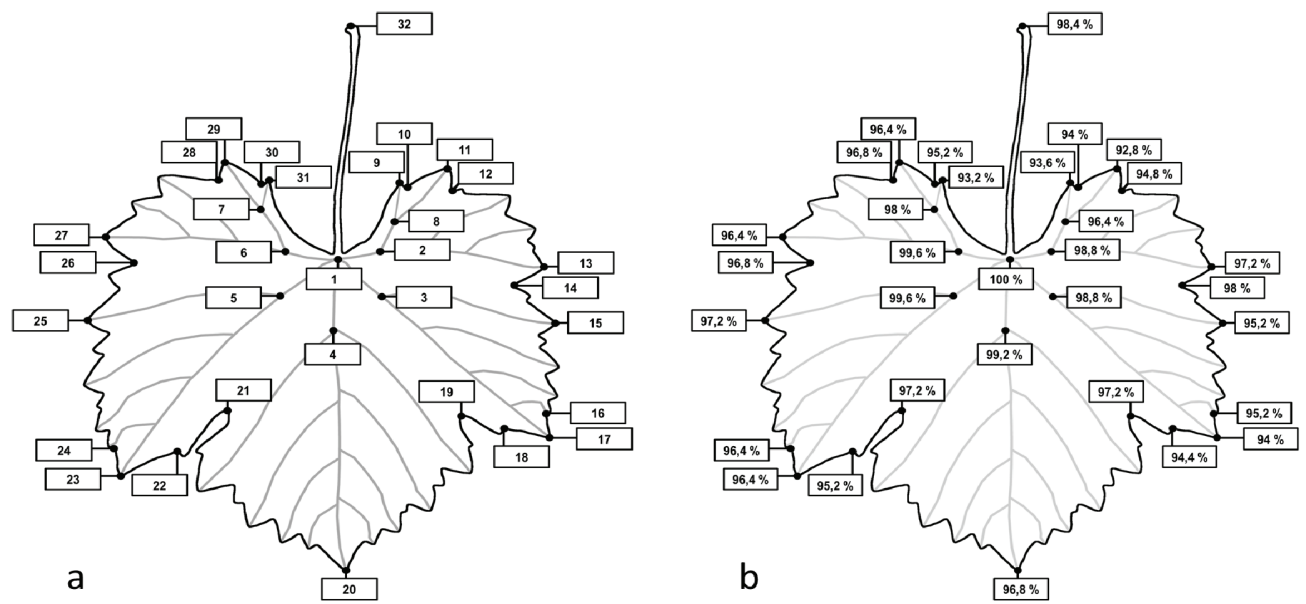

Fig. 2. Location (a) and the reliability (b) of the 32 landmarks on the collected 250 grapevine (Vitis vinifera L. cv. 'Kövidinka') leaves

\section{Evaluation of landmark and leaf morphological diversity}

Landmark coordinates show relative high deviation on the $1^{\text {st }}, 5^{\text {th }}$ and $25^{\text {th }}$ nodes, while on the $10^{\text {th }}, 15^{\text {th }}$, and $20^{\text {th }}$ the coordinates are closer to each other (Fig. 3). Morphological variability of the samples was evaluated from the $1^{\text {st }}$ to the $25^{\text {th }}$ leaf samples. Among the 54 leaf morphological characteristics all significantly differed along the shoot axis except for 4 angular characters: 1-901-13; 2-11日2-13; 1-201-3; 1-501-6. Coefficient of 

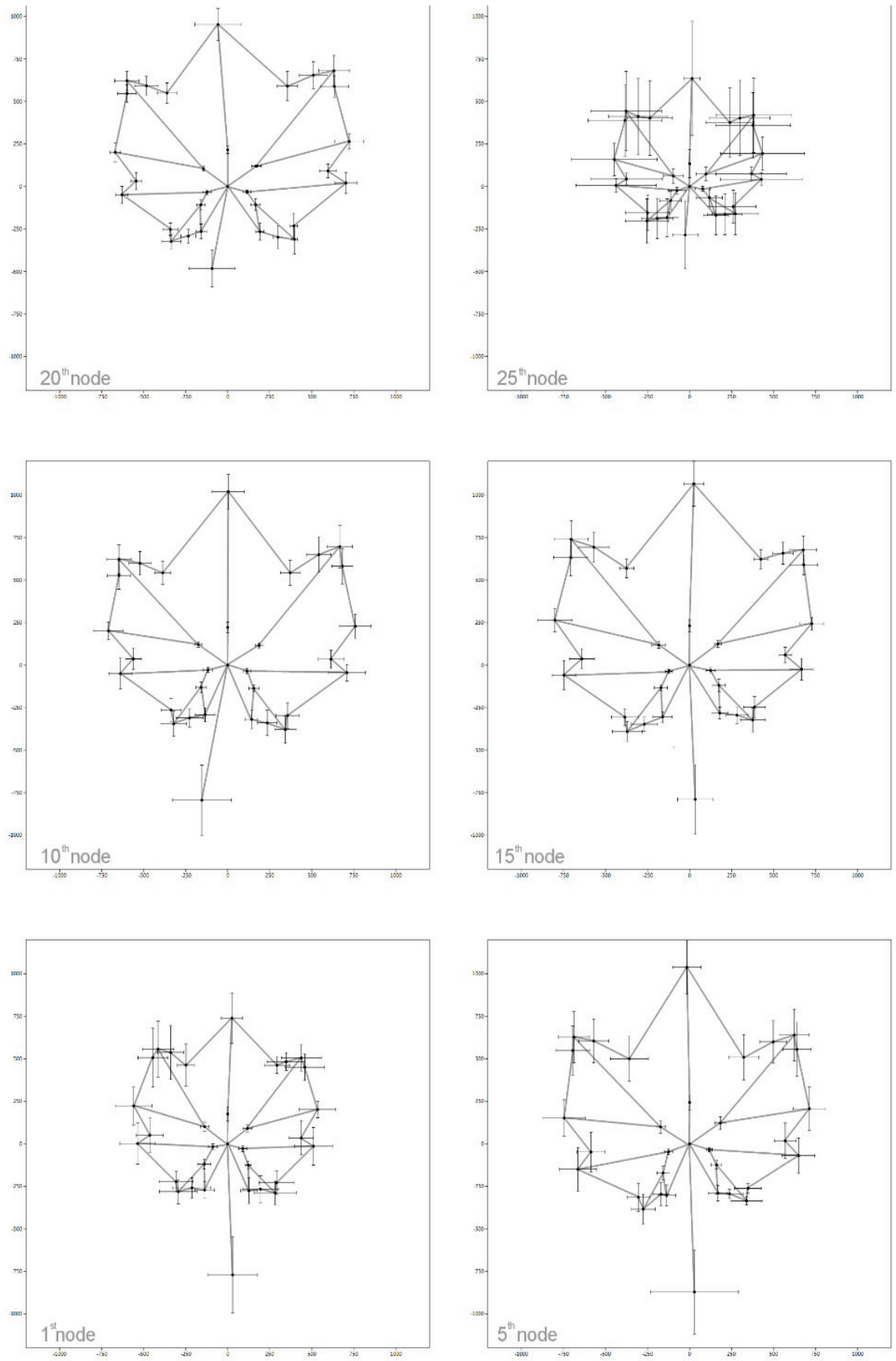

Fig. 3. Graphic reconstruction of the typical leaf shapes at $1^{\text {st }}, 5^{\text {th }}, 10^{\text {th }}, 15^{\text {th }}, 20^{\text {th }}$, and $2^{\text {th }}$ nodes based on the average and standard deviation of the Procrustes coordinates 


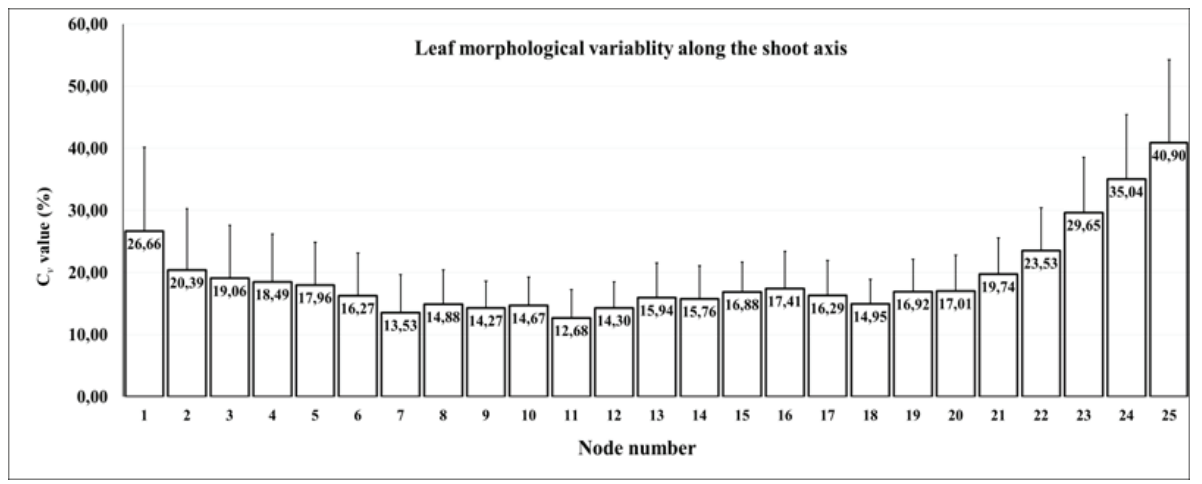

Fig. 4. Coefficient of variability of the 54 characteristics along the shoot axis

variability was calculated for the morphological characters, based on the average and standard deviation of the 54 characters. The $\mathrm{CV}$ values were the lowest on the $11^{\text {th }}$ node while the highest on the $25^{\text {th }}$ node with $12.68 \%$ and $40.90 \%$, respectively. This is in accordance with the literatures that leaf morphology shows high uniformity between the $9^{\text {th }}$ and $12^{\text {th }}$ leaves on the shoot axis (Fig. 4).

Position of the same landmarks shows differences along the leaves. Since the origin of the Cartesian coordinate system was the Lm1, its variability was 0 because it was located on the same position in the case of all samples. As distance of the coordinates increases from the base (Lm1) variability of the coordinate location is also increasing. Since position of the petiole is relative, depends on scanning procedure, its location is the most diverse (Fig. 5). Among the leaves along the shoot axis the leaves in the $24^{\text {th }}$ node showed the highest variability in the position of the same landmark coordinates while the lowest was observed at the $20^{\text {th }}$ node (data not shown).

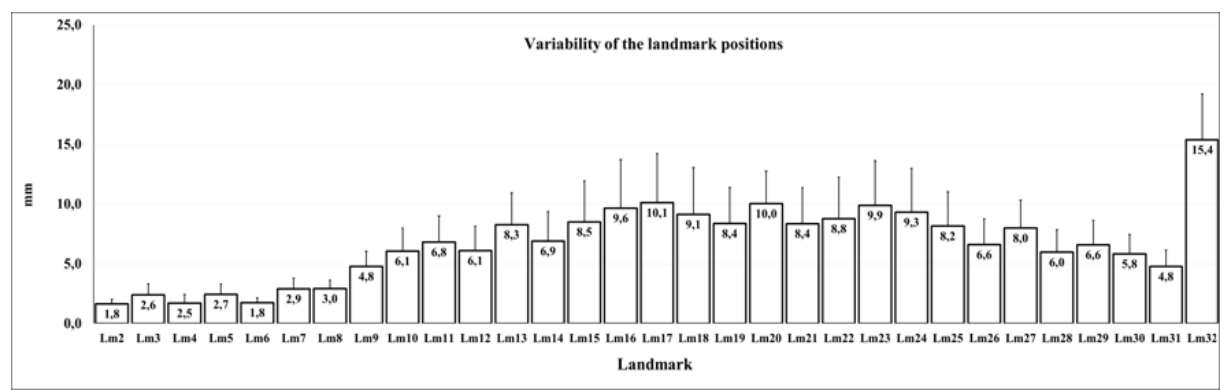

Fig. 5. Variability of the 31 landmark positions on the leaf based on the standard deviations of the coordinates at each node 


\section{Discussion}

Leaf morphology has high importance in the identification of the genus Vitis. Ampelometry has already been applied in description of species (Chitwood et al., 2016b), cultivars (Preiner et al., 2014), and clones (Nieddu et al., 2006). Since the plants show ampelometric variability along the shoot axis it is important to define the sampling position for the proper comparison of the genotypes and explain the difference among the leaf positions. Cousin and Prins (2008) have reported that V. piasezkii and its hybrids showed leaf morphological differences between the $8^{\text {th }}$ and $10^{\text {th }}$ nodes of the shoots. These results underline the morphological variability along the shoot axis. Chitwood et al. (2016b) have also reported about this phenomenon on samples collected from 12 Vitis species, $4 \mathrm{~V}$. vinifera hybrids and 3 species from the genus Ampelopsis. Their results suggest that variability is caused by multiple reasons: age of the leaves and the position of each leaf along the shoot.

In our present study leaf morphology of the grapevine cultivar 'Kövidinka' was evaluated based on 54 characters derived from 32 biometric landmarks. Our results showed that samples collected from the $11^{\text {th }}$ and $13^{\text {th }}$ nodes were the most intact without missing landmarks. Data suggest that leaf morphological characters change significantly along the shoot except for a few angular characteristics. Variabilities of these characters are decreasing from the base of the shoot to the $7^{\text {th }}$ and $11^{\text {th }}$ nodes and increase again from the $20^{\text {th }}$ node. Since landmark based morphometric evaluations are more and more frequent, presence and diversity of the landmarks on the different leaves along the shoot axis are important to be explored.

\section{Acknowledgement}

This research was supported by the ÚNKP-16-4 New National Excellence Program of the Ministry of Human Capacities. Authors are grateful for Gyula Földesi and colleagues from the Soós István Secondary School for Oenology for providing the plant material. 


\section{References}

Alessandri, S., Vignozzi, N., Vignini, A. (1996) AmpeloCADs (Ampelographic Computer-Aided Digitizing System): An integrated system to digitize and process biometrical data from Vitis spp. Leaves. Am J. Enol. Vitic. 47 (3): 257-267.

Bodor, P., Baranyai, L., Bálo, B., Tóth, E., Strever, A., Hunter, J. J., Bisztray, Gy. D. (2012) GRA.LE.D. (GRApevine LEaf Digitalization) software for the detection and graphic reconstruction of ampelometric differences between Vitis leaves. S. Afr. J. Enol. Vitic. 33 (1): 1-6.

Bodor, P., Baranyai, L., Parrag, V., Bisztray, Gy. D. (2014) Effect of row orientation and elevation on leaf morphology of grapevine (Vitis vinifera L.) c.v. Furmint. Progr. Agric. Eng. Sci. 10 (1): 53-69.

Chitwood, D. H.; Klein, L. L., O'Hanlon, R., Chacko, S., Greg, M., Kitchen, C., Miller, A. J., Londo, J. P. (2016a) Latent developmental and evolutionary shapes embedded within the grapevine leaf. New Phyt. 210: 343-355.

Chitwood, D. H.; Rundell, S. M.; Li, D. Y.; Woodford, Q. L.; Yu, T. T.; Lopez, J. R.; Greenblatt, D.; Kang, J.; Londo, J .P. (2016b) Climate and developmental plasticity: Interannual variability in grapevine leaf morphology. Plant Phys. 170. 1480-1491.

Cousins, P., Prins, B. (2008) Vitis shoots show reversible change in leaf shape along the shoot axis. Proceedings of the 2nd Annual National Viticulture Research Conference. July 9-11, 2008. University of California, Davis.

Galet, P. (1956) Cépages et vignobles de France, Tome I, Déhan, Montpellier.

Hammer, O., Harper, D. A. T., Ryan, P. D. (2001) PAST: Paleontological Statistics software package for education and data analysis. Paleontologia Electronica 4 (1): 9.

Mullins, M. G., Bouquet, A., Williams, L. E. (2003) Biology of the grapevine. Cambridge University Press. UK. pp. 239.

Németh, M. (1967) Ampelográfiai album. Termesztett borszőlőfajták 1. Mezőgazdasági Kiadó, Budapest. 236 pp.

Nieddu, G., Chessa, I., Mercenaro, L. (2006) Primary and secondary characterisation of a Vermentino grape clones collection. Environment Identities and Mediterranean Area, 2006. ISEIMA '06. First international Symposium on. DOI:10.1109/ ISEIMA.2006.34500

OIV. (2009) $2^{\text {nd }}$ edition of the OIV descriptor list for grape varieties and Vitis species. OIV 18, rue d'Aguesseau - 75008 Paris. 178.

Preiner, D., Safner, T., Karoglan Kontić, J., Marković, Z., Šimon, S., Maletić, E. (2014) Analysis of phyllometric parameters efficiency in discrimination of Croatian native V. vinifera cultivars. Vitis. 53 (4) 215-217.

R Core Team (2014) R: A language and environment for statistical computing. R Foundation for Statistical Computing, Vienna, Austria. URL: http://www.Rproject.org/.

Ravaz, L. (1902): Les Vignes Americaines: Porte-Greffes et Producteurs Directs (Caractères Aptitudes). Coulet et Fils (Montpellier). 376 pp.

Soldavini, C., Stefanini, M., Dallaserra, M., Policarpo, M., Schneider, A. (2009) SuperAmpelo, a software for ampelometric and ampelographic descriptions in Vitis. ISHS Acta Horticulturae 827. IX. Int. Conf. on Grape Genetics and Breeding. 31. May 2009. Udine, Italy. 253-258. 